\title{
Research Paper \\ Effect of a 6-week Aerobic Exercise Program on High-mobility Group Box 1 Gene Expression in Aortic Tissue of Diabetic Rats
}

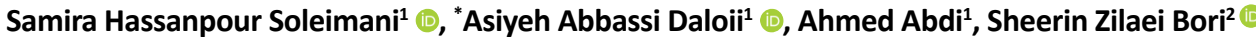

1. Department of Exercise Physiology, Ayatollah Amoli Branch, Islamic Azad University, Amol, Iran.

2. Department of Physical Education \& Sport Sciences, Masjed-Soliman Branch, Islamic Azad University, Masjed-Soleiman, Iran.

$\begin{aligned} & \text { Use your device to scan } \\ & \text { and read the article online }\end{aligned}$
mobility Group Box 1 Gene Expression in Aortic Tissue of Diabetic Rats (Persian)]. Quarterly of "The Horizon of Medical Sciences".
2021; 27(1):82-97. https://doi.org/10.32598/hms.27.1.2378.1
doil https://doi.org/10.32598/hms.27.1.2378.1

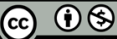

Received: 04 Jul 2016 Accepted: 18 Feb 2017 Available Online: 01 Jan 2021

Key words: Diabetes, Regular aerobic exercise, Pyroptosis, HMGB1 gene

\section{A B S TR A C T}

Aims Type 2 diabetes is a rising problem and a significant risk factor for small and large vessel disease. The present study aims to investigate the effect of a 6-week aerobic exercise program on High-mobility Group Box 1 (HMGB1) gene expression in aortic tissue of diabetic rats.

Methods \& Materials In this experimental study, 40 male rats aged 8 weeks were randomly selected. Once familiarized with the exercise protocol, they were divided into four groups of healthy-control $(n=10)$, diabetic-control $(n=10)$, healthy-exercise $(n=10)$, and diabetic-exercise $(n=10)$. Type 2 diabetes was first induced, and then the rats run on a treadmill for 6 weeks, 5 sessions per week. After $12-14 \mathrm{~h}$ of fasting and $72 \mathrm{~h}$ after the last session, aortic tissue sampling was performed for HMGB1 analysis by quantitative realtime polymerase chain reaction (q-RT PCR) technique. Data analysis was performed using 1-way ANOVA and Tukey post hoc test at the significant level of $P<0.05$.

Findings Induction of type 2 diabetes led to a significant increase in HMGB1 gene expression in rats $(P=0.001)$, significantly reduced following aerobic exercise $(P=0.003)$. Aerobic exercise also reduced the expression of the HMGB1 gene in healthy rats $(P=0.000)$.

Conclusion Aerobic exercise may have a protective effect by reducing the HMGB1 gene expression in the aortic tissue of diabetic rats. It can be used as an effective non-pharmacological method to improve diabetes-induced inflammation and prevent vascular disorders.

\section{Extended Abstract}

\section{Introduction}

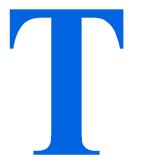

ype 2 diabetes is a rising problem and a significant risk factor for small and large vessel disease [1]. Currently, inflammatory processes play a key role in all complications of diabetes. It has now been shown that inflammation is not limited to the host's pathogen control but occurs in the absence of viral or bacterial pathogens and is associated with hyperglycemia complications [2]. One study has shown that diabetes is a significant risk factor for atherosclerosis, with an incidence of 2-4 times higher than that in the non-diabetic population [3]. Adhesion and plaque formation in the arteries causes endothelial dysfunction. There are several reports on the role of systemic inflammation in the development of atherosclerosis. In these patients, the expression and plasma concentration of inflammatory factors and their mediators increase [4]. Data from analysis of rodent and human atherosclerotic plaques have shown that

\section{* Corresponding Author:}

Asiyeh Abbassi Daloii, PhD.

Address: Department of Physical Education and Sport Science, Ayatollah Amoli Branch, Islamic Azad University, Amol, Iran.

Tel: +98 (911) 1274366

E-mail: abbasi.daloii@gmail.com 
interleukin (IL)-1 $\beta$ and IL-18, both are NLRP3 inflammasome activation products, play a vital role in the initiation and progression of atherosclerosis. Deficiency of IL-1 $\beta$ or IL-18 and delivery of the antagonist to the IL-1 $\beta$ receptor reduces the amount of atherosclerotic lesion [5].

Pyroptosis is a pre-inflammatory form of regulated cell death. It is dependent on the enzymatic activity of inflammatory proteases belonging to the family of cysteine-dependent aspartate-directed proteases (caspases). Pyroptosis is morphologically, mechanically, and pathophysiologically distinct from other cell death forms, apoptosis, and necrosis. It is characterized by rapid rupture of the plasma membrane, resulting in the release of intracellular contents and proinflammatory mediators, including IL-1 $\beta$, IL-18, and HMGB1. Recent studies have shown that pyroptosis may be involved in atherosclerosis and play an essential role in the instability of atherosclerotic lesions [6]. HMGB1, one of the higher members of the HMG protein family, was initially considered an essential mediator for maintaining chromosome structure and stability in various cells, including eukaryotic cells [7]. As a proinflammatory cytokine, the extracellular transmission of HMGB1 during inflammatory responses significantly increases serum levels in patients with inflammatory disorders [8]. Diabetes mellitus is also associated with inflammatory dysfunction, and HMGB1 has been reported to be associated with diabetes mellitus or high glucose conditions [9, 10]. HMGB1 levels increase in vitreous fluid and extraretinal membranes of diabetic retinopathy [7].

Studies have shown that exercise positively affects metabolic parameters such as insulin sensitivity, lipid profile, and endothelial function $[11,12]$. These metabolic parameters and endothelial dysfunction are useful in developing coronary artery disease and stroke [13]. Exercise plays an essential role in controlling inflammatory diseases such as diabetes by reducing the secretion of inflammatory cytokines and increasing the secretion of anti-inflammatory cytokines [14]. Aerobic exercise reduces HMGB1 levels in the blood and tissue of diabetic rats [15] and blocks the middle cerebral artery in an experimental model of rats [16]. However, finding the exact mechanisms of aerobic exercise effects on HMGB1 gene expression and related mechanisms requires further studies in diabetic patients. Therefore, this study aimed to investigate the impact of 6 weeks of aerobic exercise on the expression of the HMGB1 gene in the aortic tissue of healthy and diabetic rats.

\section{Materials and Methods}

Study samples

This experimental study was performed on 40 male Wistar rats aged 8 weeks with a Mean \pm SD of weight of $200 \pm 20 \mathrm{~g}$. They were prepared from the Physiology Research Center in Ahvaz, Iran. They were randomly divided into four groups: healthy-control, diabetic-control, healthy-exercise, and diabetic-exercise. They were kept in the Animal Laboratory of the Physiology Department of Ahvaz University of Medical Sciences under controlled conditions: 12:12 light-dark cycle (light on at $6 \mathrm{AM}$, light off at $6 \mathrm{PM}$ ), a temperature of $22^{\circ} \mathrm{C} \pm 3^{\circ} \mathrm{C}$, and humidity of about $45 \%$. Three to five rats were kept in Plexiglas cages with mesh doors and a dimension of $25 \times 27 \times 43 \mathrm{~cm}$ such that they had free access to water and food. All experiments on rats were performed according to the guidelines of the Animal Ethics Committee of Ahvaz Jundishapur University of Medical Sciences. Throughout the study, the rats were moved and manipulated only by one person.

\section{Induction of diabetes}

To induce type 2 diabetes, the rats were first injected intraperitoneally with nicotinamide $120(\mathrm{mg} / \mathrm{kg})$. Fifteen minutes later, $60 \mathrm{mg} / \mathrm{kg}$ streptozotocin (STZ) dissolved in normal $0.1 \mathrm{M}$ citrate buffer was injected intraperitoneally. Then, to ensure that the animal had become diabetic, the amount of blood glucose was assessed $72 \mathrm{~h}$ after STZ injection using a glucometer. Rats with a fasting blood sugar greater than $250 \mathrm{mg} / \mathrm{dL}$ were considered diabetic [17]. Due to the risk of STZ-induced hypoglycemia, the rats received $10 \%$ glucose solution $6 \mathrm{~h}$ after STZ administration until 24 $\mathrm{h}$ later [18].

\section{Exercise protocol}

One week after the induction of diabetes, the rats in the exercise groups performed exercise on a treadmill for 6 weeks, 5 days a week. Before starting the main exercise and for familiarization, the rats started running on the treadmill for $10-15 \mathrm{~min}$ at a speed of $5-7 \mathrm{~m} / \mathrm{min}$ and zero inclines for two consecutive days. Two days after familiarization, the main exercise began, and the rats run on the treadmill for 6 weeks. The exercise in the first week was performed at a speed of $10 \mathrm{~m} / \mathrm{min}$ for 10 minutes. In the next few weeks, the speed and duration of running on the treadmill increased: $10 \mathrm{~m} / \mathrm{min}$ for 20 minutes in the second week, 14$15 \mathrm{~m} / \mathrm{min}$ for 20 minutes in the third week, $14-15 \mathrm{~m} / \mathrm{min}$ for 30 minutes in the fourth week, and $18 \mathrm{~m} / \mathrm{min}$ for 30 minutes in the fifth and sixth weeks (Table 1) [19]. 


\section{Total RNA extraction}

For molecular studies of the gene expression level, RNA was extracted from tissues in all study groups using an RNA kit (QIAGEN, Germany) according to the manufacturer's instruction. First, 200-300 Landa Kiazol QIAzol was added to the tissue and kept at $-80^{\circ} \mathrm{C}$ for $24 \mathrm{~h}$. After $24 \mathrm{~h}$, the cryotube's plaque was crushed in a semi-frozen state by a sampler and was then slightly pipetted. About 100 Landa chloroforms were then added to the sample to lys the cells. This solution should be in contact with the cells for about 1 minute. After 1 minute, the solution was centrifuged at 12,000 rpm for 10 minutes (Hettich, Germany). After centrifugation, the solution was divided into three parts: 1) upper part of the tube, which was clear and contained RNA, 2) middle part of the tube, which was white and included the tissue cell lysis, and 3) lower part of the tube was pink that contained QIAzol.

The clear liquid at the top of the tube containing the RNA was gently removed and placed in a DEPC-treated microtube.1CC of isopropanol was then poured onto clear RNA and stirred by hand for 1 minute. Isopropranol is clear and RNA is clear, but when the two are mixed together, they form a turbid liquid. It is better to put the obtained solution at -80 degrees overnight. After adding isopropanol, the samples were centrifuged at $12000 \mathrm{rpm}$ for $10 \mathrm{~min}$. After removing the centrifuge, the supernatant was drained, and $1 \mathrm{~mL}$ of $70 \%$ alcohol was added. After vortexing, the mixture was centrifuged at $7500 \mathrm{rpm}$ for $10 \mathrm{~min}$. The supernatant was then drained with a sampler, and then the plaque was dried inside the microtube. To dissolve RNA, 20 Landa of $60^{\circ} \mathrm{C}$ distilled water was poured on the plate inside the microtube. It was then pipetted slightly with a sampler and placed on a $60^{\circ} \mathrm{C}$ plate for 5 minutes. The extracted RNA was maintained at $-80^{\circ} \mathrm{C}$ until further use.

\section{Synthesis of cDNA}

After extracting RNA with high purity and concentration from all studied samples, cDNA synthesis steps were performed using a cDNA synthesis kit (Fermentas, USA) according to the manufacturer's instructions. Then, the synthesized cDNA was used for reverse transcription reaction. First, all designed primers related to all genes were examined, and then gene expression was analyzed using the quantitative real-time polymerase chain reaction (q-RT PCR) method.

\section{Polymerase chain reaction}

Primers were prepared in lyophilized form. To make the primers, a specific volume of sterile distilled water was add- ed to each tube containing the lyophilized primer (based on information about each primer). This solution was placed as a stock at $-20^{\circ} \mathrm{C}$. To perform each test, the following materials with the mentioned concentrations were poured into the 48-well containers and mixed: $10 \mu \mathrm{L}$ SYBER Green + Master Mix (ABI, USA), $10 \mathrm{pmol}(0.5 \mathrm{~mL})$ forward primer, 10 pmol $(0.5 \mathrm{~mL})$ reverse primer, $1 \mu \mathrm{L}$ cDNA, and $8 \mu \mathrm{L}$ DEPC-treated water. The samples were kept on ice until transfer to the device.

\section{Molecular measurement of gene expression}

As mentioned above, the q-RT PCR method (ABI StepOne, Applied Biosystems) was used for measuring gene expression. For this purpose, using QIAzol solution, the RNA of all cells was extracted according to the CinnaGen protocol and exposed to DNase I (Fermentas, USA) to ensure infection with genomic DNA. Then the quality of extracted RNAs was evaluated by a spectrophotometer (DPI1, QIAGEN, Germany). To prepare cDNA, a single-strand Oligo (dt) primer (MWG-Biotech, Germany) and reverse transcription enzyme (Fermentas, USA) were used according to the related protocol. Each PCR was performed using PCR Master Mix (Applied Biosystems), SYBR Green (ABI StepOne, Applied Biosystems), and Sequences Detection Systems (Foster City, CA, USA) according to the manufacturers' protocol. Forty cycles were considered for each q-RT PCR cycle, and the temperature of each cycle was set as $94^{\circ} \mathrm{C}$ for 20 seconds, $58^{\circ} \mathrm{C}-60^{\circ} \mathrm{C}$ for 30 seconds, and $72^{\circ} \mathrm{C}$ for 30 seconds. The melting diagram was plotted to evaluate the accuracy of PCRs and was evaluated specifically with a negative control diagram for each gene to check for contamination in each reaction.

\section{Data analysis}

Descriptive statistics (frequency, mean, and standard deviation) were used for describing data. The KolmogorovSmirnov (KS) test was used to determine the normality of data distribution, and Levene's test measured the equality of variances. The one-way ANOVA and Tukey post hoc test was used to determine the significant differences between variables and their interaction. Findings were evaluated at a 95\% confidence level $(\mathrm{P}<0.05)$. All statistical analyses were performed in SPSS V. 21.

\section{Results}

The mean and standard deviation of HMGB1 levels in different study groups are presented in Table 3 . The results showed that the highest levels of HMGB1 belonged to the diabetic-control group and the lowest levels to the healthyexercise group. Since the KS results (Table 3) and Lev- 
Table 1. Aerobic exercise protocol

\begin{tabular}{|c|c|c|}
\hline Week & Duration (min) & Speed (m/min) \\
\hline 1 & 10 & \multirow{3}{*}{10} \\
\hline & & \\
\hline 2 & 20 & \\
\hline 3 & 20 & \multirow{3}{*}{$14-15$} \\
\hline & & \\
\hline 4 & 30 & \\
\hline 5 & 30 & \multirow{3}{*}{18} \\
\hline & & \\
\hline 6 & 30 & \\
\hline
\end{tabular}

Table 2. List of primers sequences

\begin{tabular}{cc}
\hline Gene & \multicolumn{1}{c}{ Sequence } \\
\hline$r$-Hmgb1-f & TGAAATGTAGGGCTGTGTAAGA \\
$r$-Hmgb1-r & TGTACTAGGCAAGGTTAGTGG \\
\hline & $\begin{array}{l}\text { Quarterly of } \\
\text { The Horizon of Medical Sciences }\end{array}$
\end{tabular}

Table 3. The mean and standard deviation of HMGB1 levels in different study groups

\begin{tabular}{ccccccccc}
\hline Group & Diabetic-control & $\mathbf{P}^{*}$ & Diabetic-exercise & $\mathbf{P}^{*}$ & Healthy-exercise & $\mathbf{P}^{*}$ & Healthy-control & $\mathbf{P}^{*}$ \\
\hline Mean & 0.401 & & 0.147 & & 0.049 & & 0.114 & 0.551 \\
Standard deviation & 0.103 & 0.802 & 0.037 & 0.386 & 0.013 & 0.139 & 0.029 & \\
\hline
\end{tabular}

* The Shapiro-Wilk test.

Quarterly of

The Horizon of Medical Sciences

Table 4. Results of 1-way ANOVA for comparison of study groups in terms of HMGB1 level

\begin{tabular}{cccccc}
\hline Source & Sum of Squares & df & Mean Square & F & Sig. \\
\hline Between-group & 0.216 & 3 & 0.072 & 22.053 & 0.000 \\
Within-group & 0.026 & 8 & 0.003 & & \\
\hline Total & 0.242 & 11 & & $\begin{array}{l}\text { Quarterly of } \\
\text { The Horizon of Medical Sciences }\end{array}$
\end{tabular}

ene's test $(\mathrm{P}=0.106)$ indicated normal data distribution and equality of variances, respectively, so the test conditions were established. The results of 1-way ANOVA (Table 4) indicated a significant difference in HMGB1 levels between different study groups $(\mathrm{F}=22.053, \mathrm{P}=0.000)$. Overall, induction of diabetes caused a significant increase in aortic tissue's HMGB1 gene level, and then aerobic exercise significantly reduced its level. However, it was still far from the gene expression level of healthy rats. Aerobic exercise also reduced the expression of the HMGB1 gene in healthy rats.

The mean and standard deviation of blood glucose levels in the study groups are shown in Table 5. Tukey post hoc test was used to examine which groups differed from each other (Table 6). There was a significant difference between the mean blood glucose level between diabetic-control, healthy-exercise, and diabetic-exercise, such that the mean 
Table 5. The Mean \pm SD of blood glucose levels in different study groups

\begin{tabular}{|c|c|c|}
\hline \multirow{2}{*}{ Group } & \multicolumn{2}{|c|}{ Blood Glucose (mg/dL) } \\
\hline & $\mathbf{N}$ & Mean $\pm S D$ \\
\hline Healthy-control & 10 & $110.11 \pm 4.64$ \\
\hline Healthy-exercise & 10 & $93.25 \pm 5.32$ \\
\hline Diabetic-control & 10 & $271.81 \pm 23.52$ \\
\hline Diabetic-exercise & 10 & $187.13 \pm 14.83$ \\
\hline
\end{tabular}

Table 6. Tukey Post Hoc Test results

\begin{tabular}{|c|c|c|c|c|c|}
\hline Dependent variable & Group I & Group J & Mean difference (I-J) & Standard error & Sig. \\
\hline \multirow{5}{*}{ Blood glucose level } & & Diabetic-control & -161.700 & 5.364 & 0.000 \\
\hline & Heathy contorol & Healthy-exercise & 16.860 & 5.364 & 0.031 \\
\hline & & Diabetic-exercise & -77.020 & 5.364 & 0.000 \\
\hline & Heathy exercise & Diabetic-exercise & -93.880 & 5.364 & 0.000 \\
\hline & Diabetic contorol & Diabetic-exercise & 84.680 & 5.364 & 0.000 \\
\hline
\end{tabular}

blood glucose of the healthy-control group was higher than that of the healthy-exercise group and lower than that of diabetic-control and diabetic-exercise groups. There was also a significant difference in mean blood glucose level between the healthy-exercise and the diabetic-exercise groups, where it was lower in the healthy-exercise group. Furthermore, there was also a significant difference in the mean blood glucose level between the diabetic-control and diabetic-exercise groups, where it was higher in the diabetic-control group.

\section{Discussion}

In this study, induction of diabetes led to a significant increase in the expression level of the HMGB1 gene in the aortic tissue of rats. Then aerobic exercise significantly reduced its level. Aerobic exercise also reduced the gene expression in healthy rats. HMGB1 is involved in many physiological and pathological processes, such as DNA repair, transcription, and extracellular signal transduction [15]. In normal tissues, most cells express none or only low levels of HMGB1 [20]. Transfer of HMGB1 from the nucleus to the cytoplasm and further out of the cell occurs only in pathological conditions (ischemia, trauma, hyperglycemia, etc.) [21]. High blood sugar causes oxidative stress, which leads to the activation of NF- $\mathrm{KB}$ (nuclear factor kappa-light-chain-enhancer of activated B cells) and thus increases the level of proinflammatory cytokines. A study has shown an increase in serum levels of TNF- $\alpha$ (tumor necrosis factor-alpha) and C-reactive protein due to diabetes induction [22]. Studies have shown a significant rise in HMGB1 by glucose, which is associated with the upregulation of proinflammatory cytokines by activating the NF- $\mathrm{KB}$ signaling pathways, and HMGB1 inhibition strategy reduces proinflammatory cytokines in response to high glucose by inhibiting the NF- $\kappa B$ signaling pathways. This issue indicates the regulatory role of HMGB1 in inflammatory responses in diabetic patients [9]. Increased blood glucose leads to increased expression of HMGB1 and TNF- $\alpha$ genes [23]. Studies have shown that proinflammatory cytokines such as TNF- $\alpha$ impair insulin signaling in insulin-sensitive tissues. Elevated systemic levels of the anti-inflammatory cytokine IL-10 have been reported to protect skeletal muscle from the secretion of diabetes-associated macrophages, increased inflammatory cytokine TNF- $\alpha$, and the adverse effects of these cytokines on insulin signaling and glucose metabolism, and therefore associated with increased insulin sensitivity [24]. Exercise stimulates the production of anti-inflammatory cytokines such as IL-10 and reduces the production of proinflammatory cytokines such as TNF- $\alpha$, 


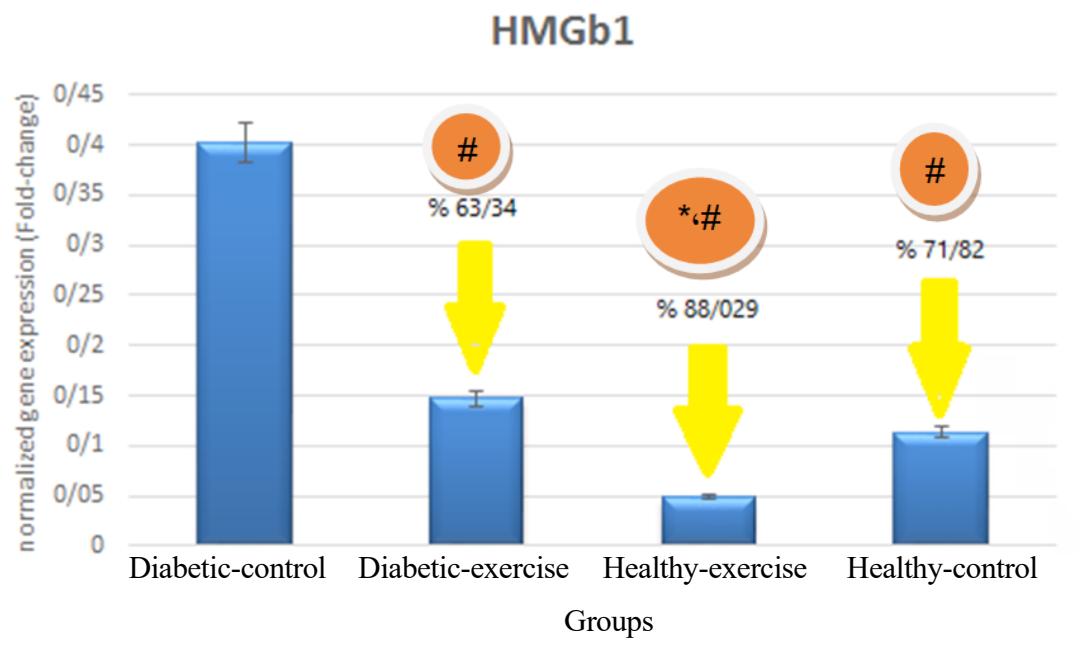

Figure 1. Comparison of mean HMGB1 levels in different study groups

Quarterly of

\# Significant difference compared to the diabetic-control; * Significant difference compared to the healthy-control.

thus playing an essential role in controlling diabetes. Studies have suggested that exercise may indirectly increase IL10 affecting the secretion of other inflammatory and antiinflammatory cytokines, such as IL-16 [25].

Yu et al. indicated the role of HMGB1 protein in the development of diabetic retinopathy [23]. HMGB1 is a highly conserved protein. It has been reported that multiple pathological stimuli, in addition to necrosis, may cause HMGB1 to leave the cell. Related studies have shown that HMGB1 can not only enhance the inflammatory response but can also stimulate the formation of new blood vessels [26]. In the study byYu et al. [23], the expression of the HMGB1 gene was significantly higher in diabetic rats than in controls. They showed that HMGB1 was 6.1 times more expressed in the retinal cells of diabetic rats. This suggests that long-term hyperglycemia may stimulate HMGB1 gene expression and that HMGB1 may contribute to diabetic retinopathy in rats. Some studies have shown that HMGB1 and ROS are more expressed in the retina under acute ischemia-reperfusion injury $[27,28]$. Volz found that, although HMGB1 in rats with diabetic retinopathy changed later compared to other inflammatory factors such as VEGF, it had a longer shelf life [29]. This suggests that the HMGB1 protein may be involved in the later stages of diabetic retinopathy. It was recommended that HMGB1 might be involved in inflammation and new vascular formation in diabetic retinopathy through binding to advanced glycation end products (RAGE) and TLR2 receptors $[28,30]$. HMGB1 may be involved in diabetes through receptor binding, and HMGB1 content is directly related to retinal cell apoptosis. Diagnosis of HMGB1 levels and its treatment in clinics can help predict and treat the complications of diabetes. In the present study, the induction of diabetes significantly increased the expression of the HMGB1 gene in aortic tissue, which may lead to endothelial dysfunction in rats.

On the other hand, regular aerobic exercise led to a significant reduction in the HMGB1 gene. In line with our study, Pan et al. showed that exercise on a treadmill reduced the transfer of HMGB1 to the cytoplasm. HMGB1 showed a positive feedback loop, causing autophagy [15]. OGD activates autophagy in PC12 cells and recombinant HMGB1 (rHMGB1) increases the binding of HMGB1 to Beclin1, thereby increasing LC3 expression and increasing the autophagy flux. Studies have shown that exercise reduces gene expression Cytokine IL-1 $\beta$ [31]. Previous studies have also shown that treadmill exercise affects serum HMGB1 level [16]. This finding indicates another mechanism that treadmill exercise regulates HMGB1 expression. Recently, HMGB1, as an essential proinflammatory factor in pathological conditions, has been studied in animal models and clinical settings [32]. Extracellular HMGB1 recognizes receptors such as RAGE and TLR2/4, and further activates the $\mathrm{NF}-\mathrm{\kappa B}$ signaling pathway, and promotes inflammatory responses [33]. Studies have shown that exercise reduces gene expression Cytokine IL-1 $\beta$. Hence, it is possible that exercise decreases the inflammatory response through HMGB1 and exerts its protective effect $[16,34]$.Pan et al. reported that aerobic exercise reduces cardiac tissue HMGB1 protein in diabetic patients [15], and Gialoria et al. reported a decrease in this gene in patients with myocardial infarction [35]. Heat shock proteins (HSPs) increase after exercise.

On the other hand, they are effective in reducing the expression of HMGB1 and the cytoplasmic transmission and secretion of HMGB1 [36]. Therefore, one of the possible mechanisms of HMGB1 reduction in the aortic tissue of 
diabetic rats following aerobic exercise can be an increase in the HSP level. Despite reduced HMGB1 gene expression in the aortic tissue of diabetic rats by aerobic exercise, the gene level was still far from the level in healthy rats. Therefore, it is suggested that in future studies, while increasing the study period, the use of other effective nonpharmacological interventions, including the use of herbal supplements, be useful in further reducing this gene level in the healthy rats.

\section{Conclusion}

Six weeks of aerobic exercise reduced HMGB1 gene expression in the aortic tissue of diabetic rats. Therefore, aerobic exercise can be an effective non-pharmacological method to improve inflammation caused by diabetes and prevent vascular disorders. A definite statement requires further studies in this field.

\section{Ethical Considerations}

Compliance with ethical guidelines

This study was approved by the Research Ethics Committee of Islamic Azad University of Marvdasht branch (Code: IR.IAU.M.REC.1399.007).

\section{Funding}

This article was extracted from the $\mathrm{PhD}$. dissertation of Samira Hassanpour Soleimani at Amol Azad University, Faculty of Sports Sciences, majoring in Exercise Physiology (Cardiovascular and Respiratory Arteries) without funding.

\section{Authors' contributions}

Conceptualization: Asieh Abbassi-Daloei; Writing - original draft, and Writing - review \& editing: Asieh AbbassiDaloei, Samira Hassanpour, and Shireen Zilaei; Data collection and data analysis: Samira Hassanpour Soleimani; Writing, editing, and review: All authors.

\section{Conflicts of interest}

The authors declared no conflict of interest. 


\title{
اثر تمرين هوازى بر بيان ثن HMGB1 در بافت أئورت موشهاى صحرايى ديابتى
}

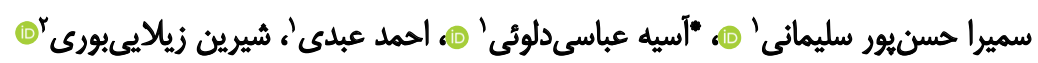 \\ ا. كروه فيزيولوزى ورزشى، واحد آيتالله آملى، دانشكاه آزاد اسلامي، آمل، ايران.

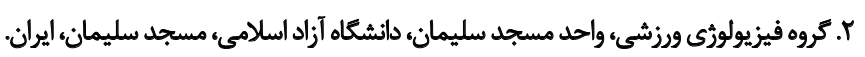

\section{حكSد}

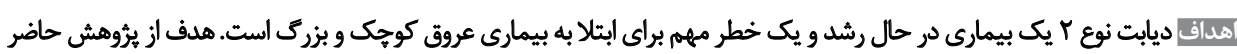

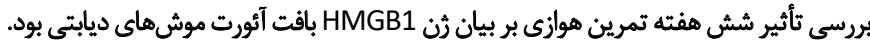

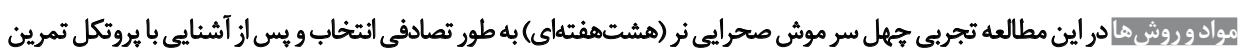

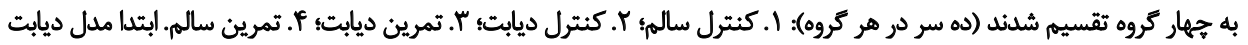

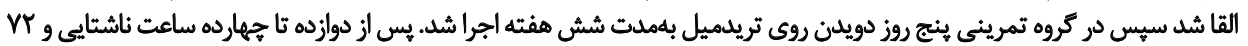

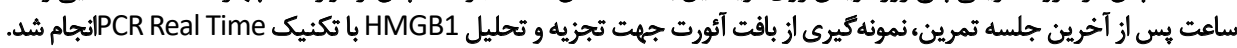

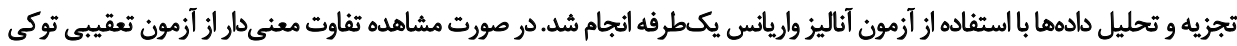

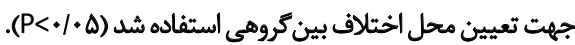

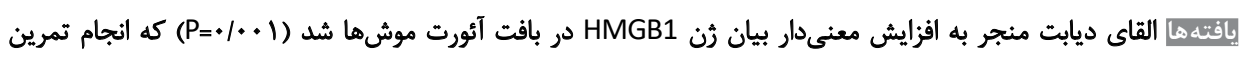

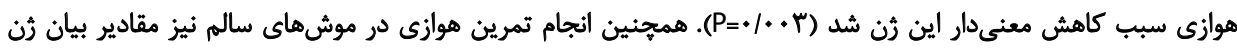

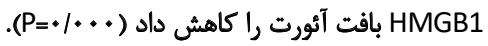

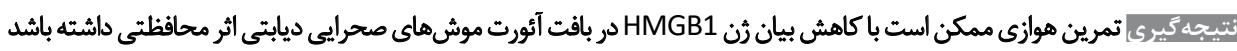

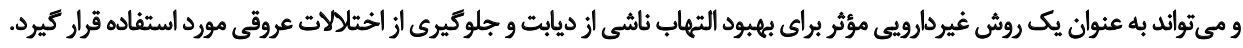

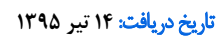

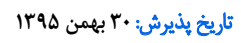

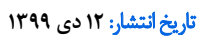

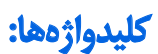

ديابت، تمرين مينظم

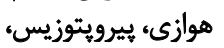
بيان ثرن HMGB1 بيرويتون

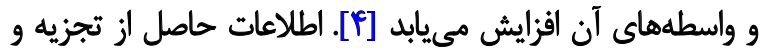

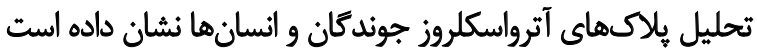

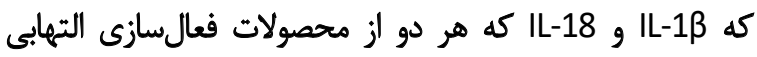

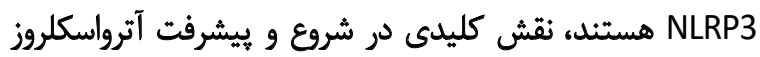

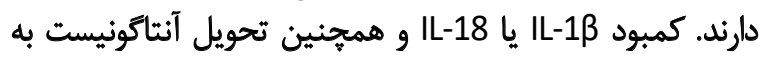

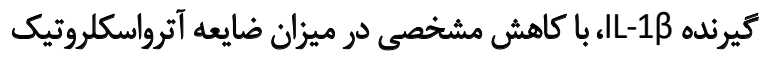

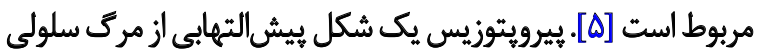

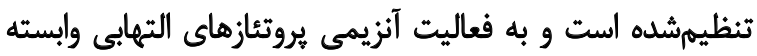

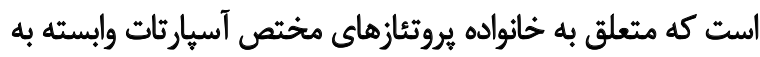

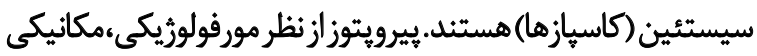

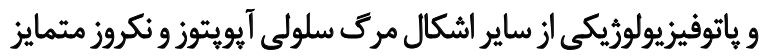

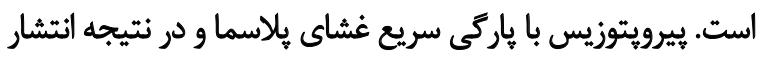

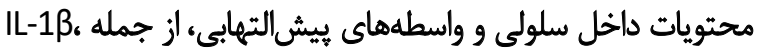

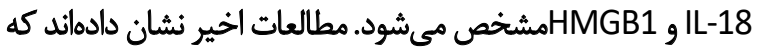

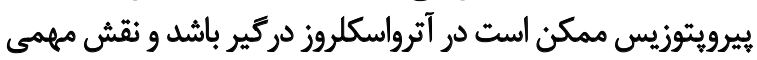

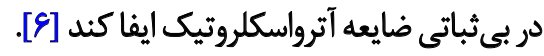

ديابت نوع Y يك بيمارى در حال رشدو يك خطر مهار بر براى

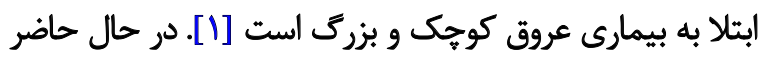

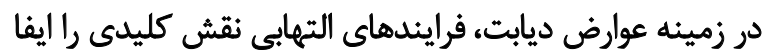

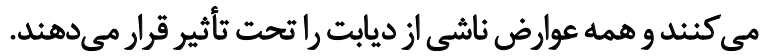

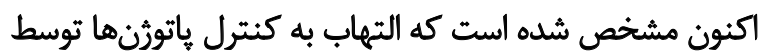

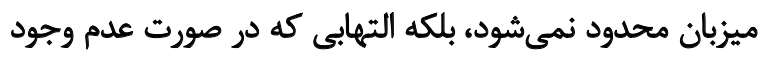

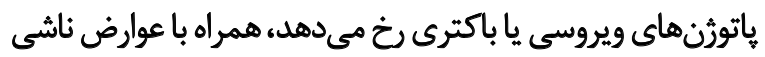

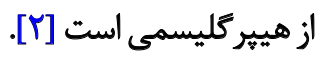

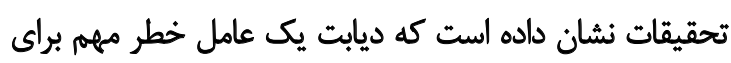

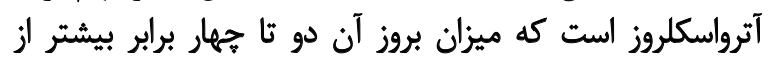

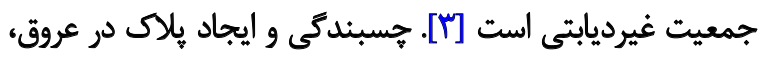

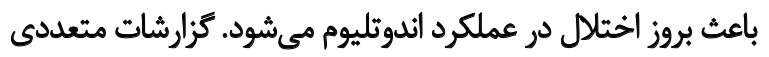

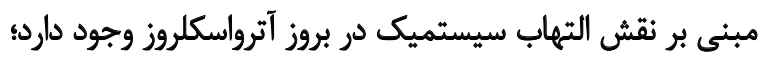
جنانكه در اين بيماران، بيان وغلظت يلاسمايى فاكتورهاى التهابى بلى

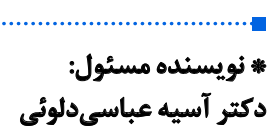

دكتر آسيه عباسى دلوئي مئى

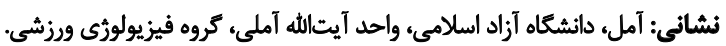

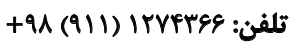
abbasi.daloii@gmail.com يست الكترونيكي: تلفئ 
رطوبت حدود هأ درصد نتخهدارى شدند. تعداد سه تا ينج عدد

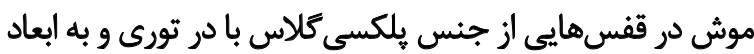

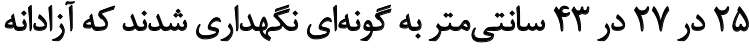

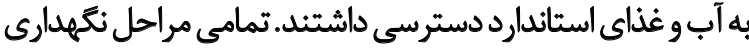

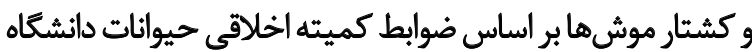

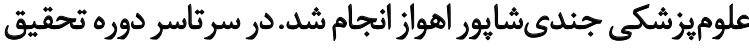
موشها توسط يك نفر جابهجا و دست كارى شدندي.

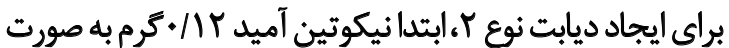

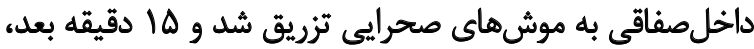

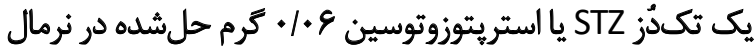

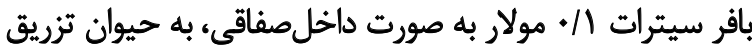

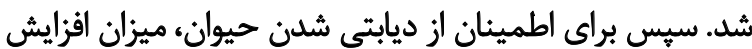

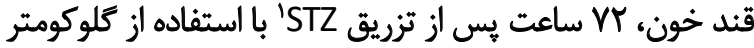

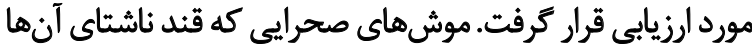

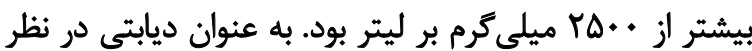

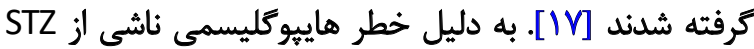

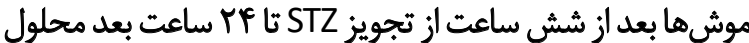

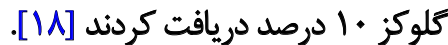

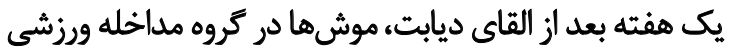

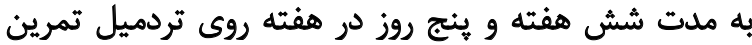

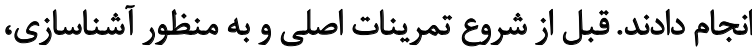

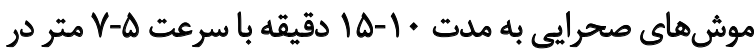

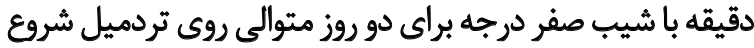
به دويدن كردند. دو روز يس از تمدئ تمرينات آشناسازى، تمرينات

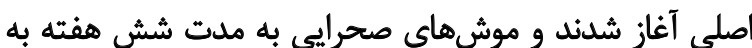

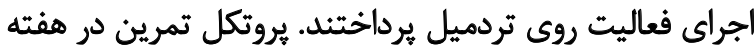

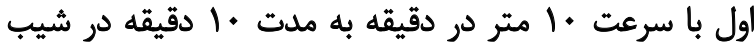

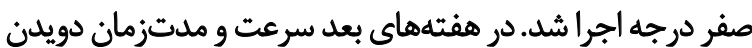

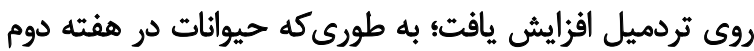

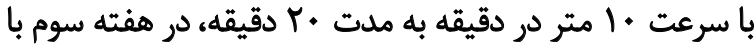

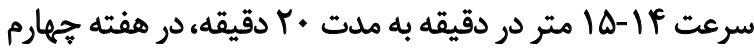

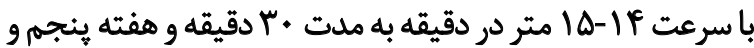

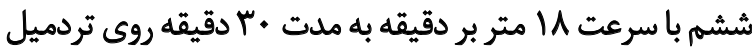

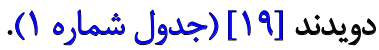

جهت بررسىهاي مولكولى در سطح بيان رُن، ابتدا استخراج

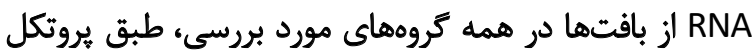
شركت سازنده (كيارن، آلمان) انجام كرفت.

ابتدا به تخمكها ...r-..+r لاندا كيازول اضافه شد و به

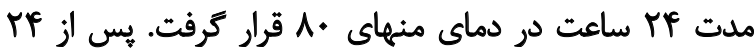

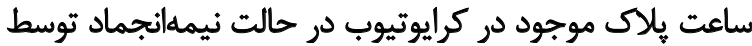

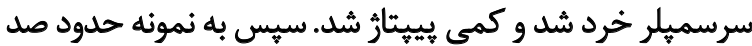

1. Streptozocin

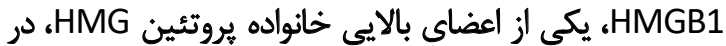

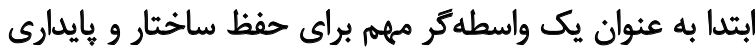

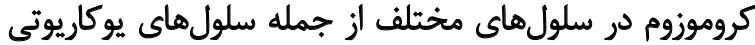

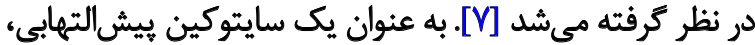

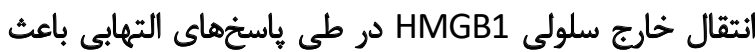

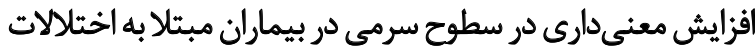

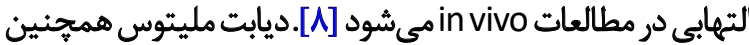

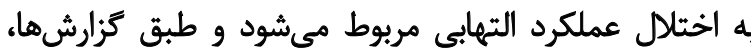

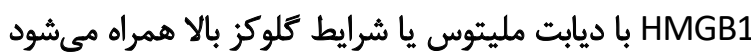

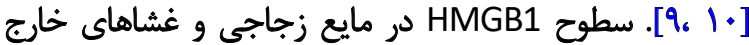

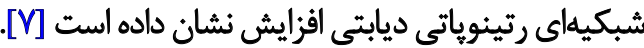
مطالعات نشان دادهاند كه تمرينات ورزشى يك اثر مطلوب روى لئري

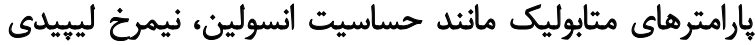

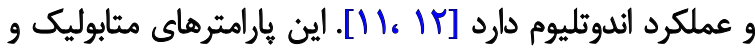

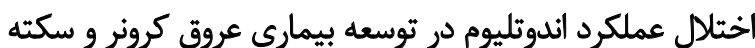

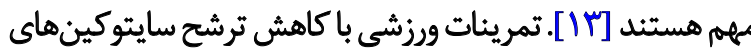

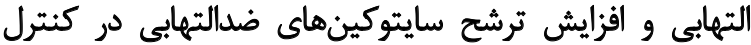

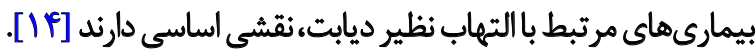

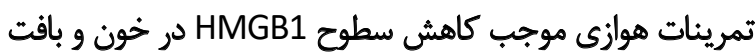

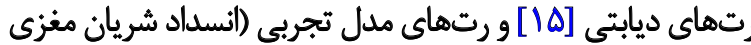

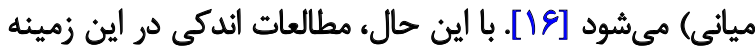

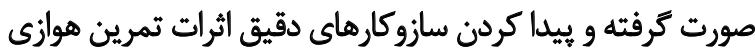

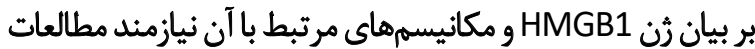

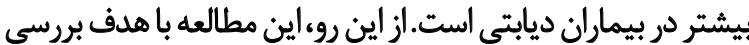

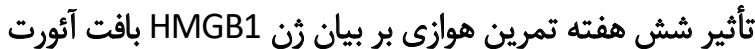
موشهاى سالم و ديابتى صورت كرفته است.

مواد وروشها

مطالعه حاضر به صورت تجربى روى موشهاي صحرايى نرنزواد

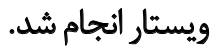

هجل سر موش صحرايي نر هشتهفتهاى با ميانكين

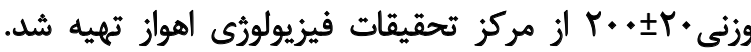

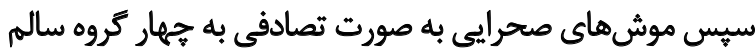

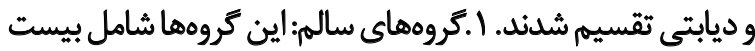

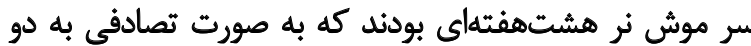

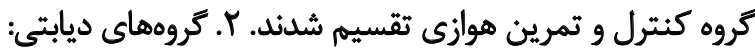

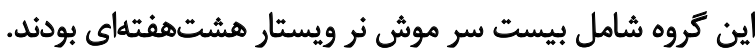
كه به صورت تصادفى به دو كروه ديابتى و ديابت + تمرين هوازى

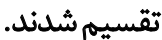

موشها در آزمايشعاه حيوانات بخش فيزيولوثى دانشعاه

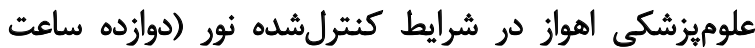

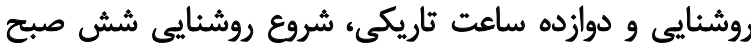

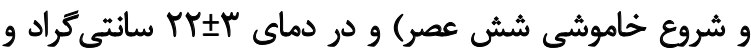


• Primer Revers 10 • (1 ييكومولار (Q/• ميكروليتر)

cDNA 1 • DEPC Water 8 •

نمونهها تا زمان انتقال به دستكاه روى يخ نكا داشته شئه شديند.

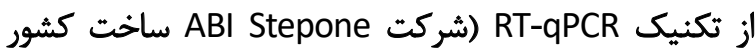

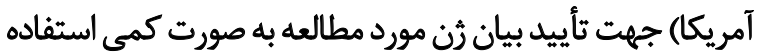

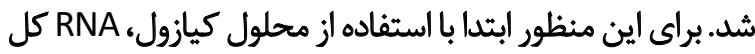

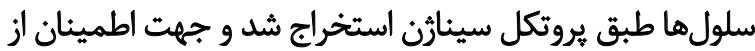

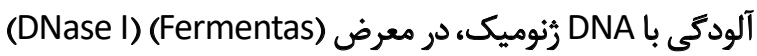

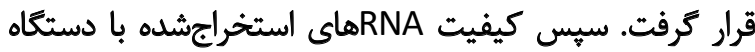

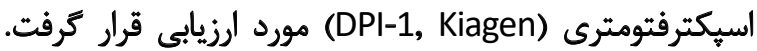
Oligo dt (MWG-) تكهت تهيه CDNA

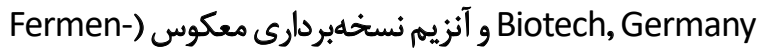

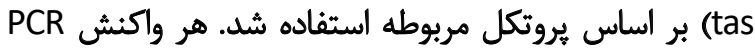
با استفاده از (APCR master mix) (Aplied Biosystems) ABI Step One (Applied) در دستكاه SYBER Green, Biosystems, Sequences Detection Systems. Focter) (City, CA

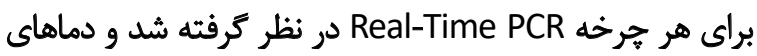

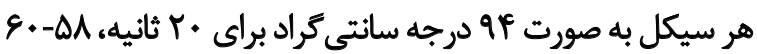

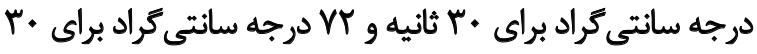

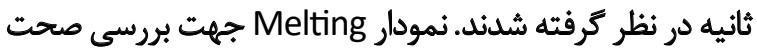

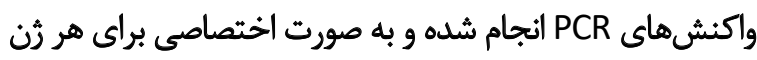

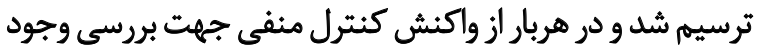
آلودىى در هر واكنش مورد ارزيابي قرار ترفت

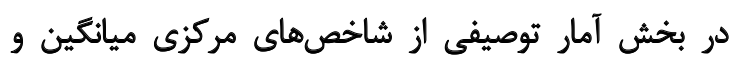

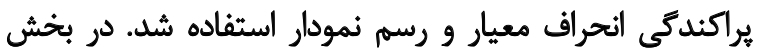

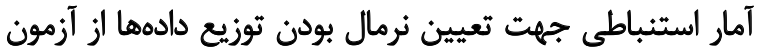

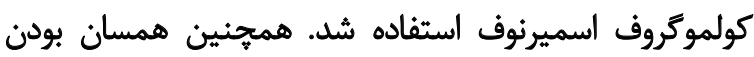

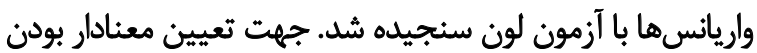

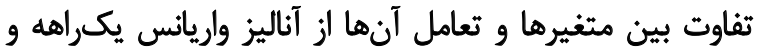

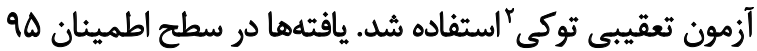

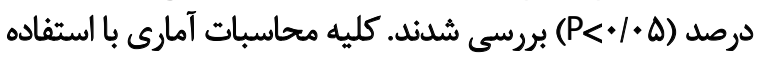
از نرم|فزار SPSS نسخه إن انجام شد.

يافتها

ميانكين و انحراف معيار سطوح HMGB1 كروههاى مختلف

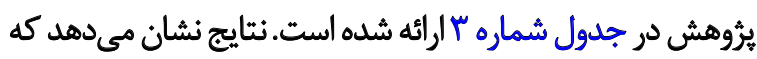

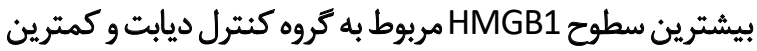

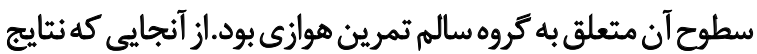

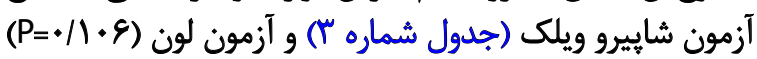

لاندا كلروفرم اضافه شد تا سلولها ليز شود. اين محلول حدود يك دقيقه با سلولها در تماس بود.

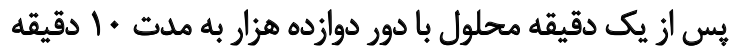
سانتريفيور (شركت Hettich كشور آلمان) شد. يس إن از سانتريفيوز

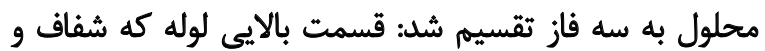

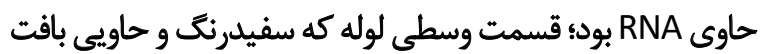
ليزشده بود؛ قسمت يايينى لوله كه صورتى و حاوى كيت كيازول بودي مايع شفاف قسمت بالايى لوله كه حاوى RNA بود بهآرامى

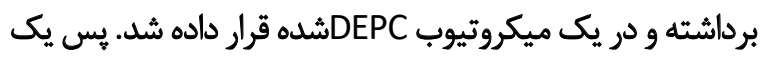

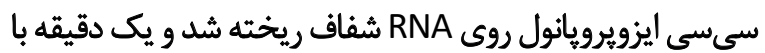

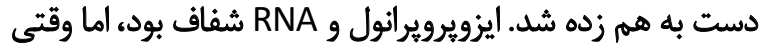

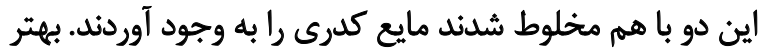
است اين محلول يك شب در دماي منهاى •1 قرار كيرد. هي از افزودن ايزويرويرانول نمونهها در سانتريفيوز بادور دوازده

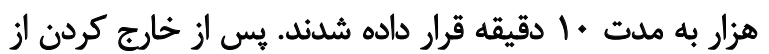

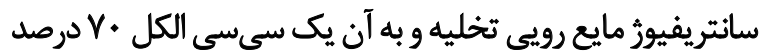

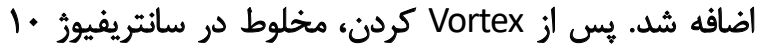

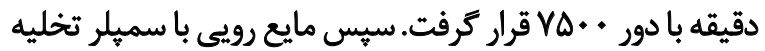

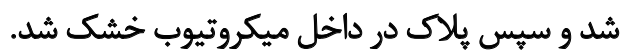

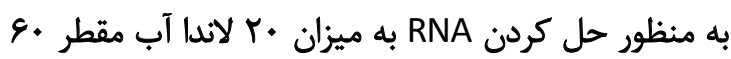

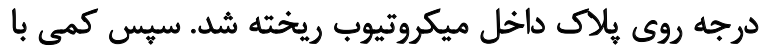

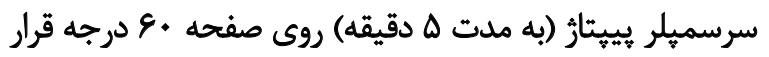

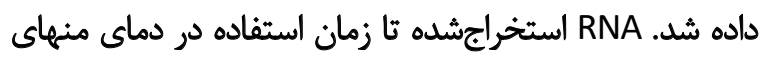

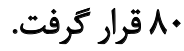

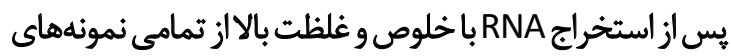

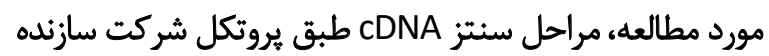
انجام كرفت و سيس بـ (Fermentas, USA) جهت انجام واكنش رونويسى معكوس مورد استفاده قرار كرفت.

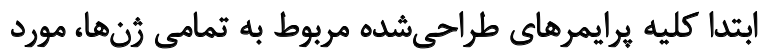

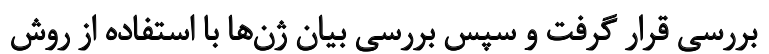

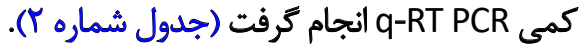
يرايمرها به صورت ليوفيليزه در دسترس قرار كرفتيند. براى براي

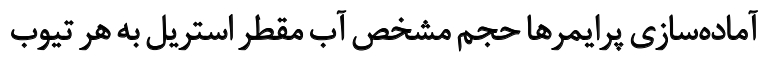

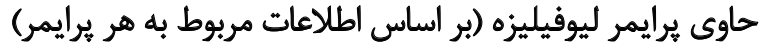

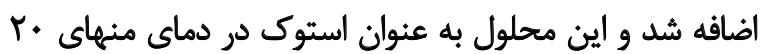

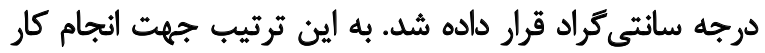

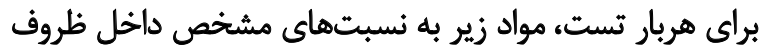

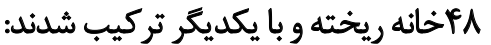

(ABI, USA) ميكروليتر CYBER Green + Master Mix 10 • Primer Forward 10 . بيكومولار (Q/• ميكروليتر) 
جدول ا. يروتكل تمرين هوازى

\begin{tabular}{|c|c|c|}
\hline سرعت تمرين & تمرين مدت & هفته \\
\hline \multirow{2}{*}{ ما متر بر دقيقه } & •ا دقيقه & هـته اول \\
\hline & r. r بقيقه & هفته دوم \\
\hline \multirow{2}{*}{ |f-1ه متر بر دقيقه } & & هفته سوم \\
\hline & . ب دقيقه & هفته جهارم \\
\hline \multirow{2}{*}{ ا متر بر دقيقه } & r ب دقيقه & هُته هِنجمَ \\
\hline & مب دقيقه & هفته ششم \\
\hline
\end{tabular}

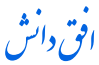

جدول r. جدول توالى برايمر

\begin{tabular}{cc}
\hline us & \multicolumn{1}{c}{ توالى } \\
\hline$r-H m g b 1-f$ & TGAAATGTAGGGCTGTGTAAGA \\
\hline$r-H m g b 1-r$ & TGTACTAGGCAAGGTTAGTGG \\
\hline
\end{tabular}

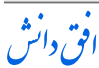

جدول ץ. شاخصهاى مركزى و يراكندكى سطوح HMGB1 در كروهاى مختلف يُروهش

\begin{tabular}{|c|c|c|c|c|c|c|c|c|}
\hline Pارزش & كثترل سالم & ارزش P P & سالم تمرين هوازى & ارزش P & ديابت تمرين هوازى & ارزش P & كثترل ديابت & كموه \\
\hline \multirow{2}{*}{$\cdot|\Delta \Delta|$} & . /IIf & \multirow{2}{*}{.$/ 1 F 9$} & $.1 .+9$ & \multirow{2}{*}{ 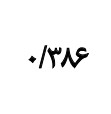 } & . /NF & \multirow{2}{*}{$\cdot / A \cdot r$} & $-\mid k+1$ & ميانكين \\
\hline & $.1 . \mathrm{rq}$ & &.$/ .14$ & & $\%+r$ & & $\cdot N \cdot r$ & انحراف معيار \\
\hline
\end{tabular}

ارزش P : مربوط به آزمون شاييروويلك.

اختلاف معنى دار وجود دارد؛ بنابراين فرضيه صفر (فرضيه تفاوت

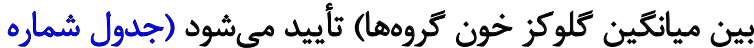

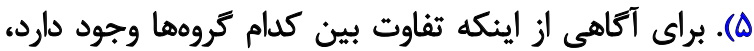

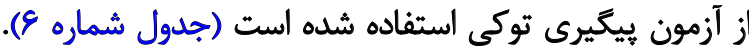

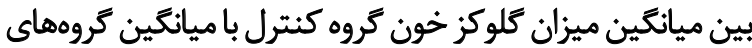

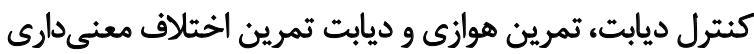

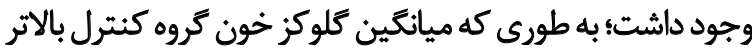

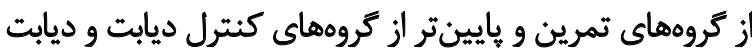

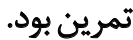

همجنين بين ميانكين كلوكز خون كروه تمرين با ميانكين

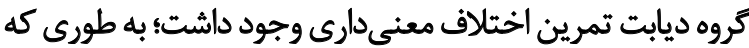

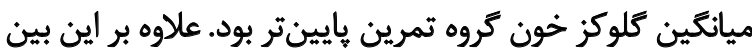

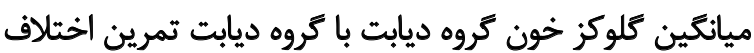

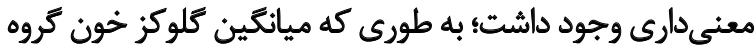

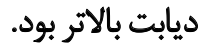

به ترتيب دلالت بر توزيع نرمال دادهها و تجانس واريانس داشتند،

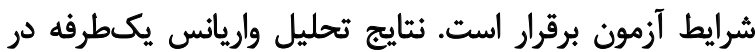

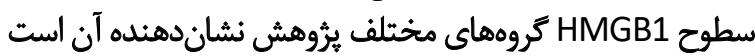

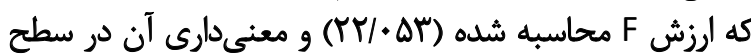

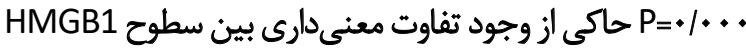
در كروهاى مختلف يروهش است.

نتايج تصوير شماره ا حاكى از آن است كه كروه كنترل دئ ديابت

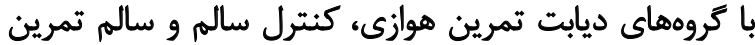

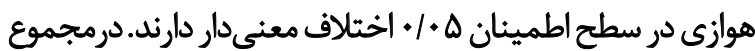

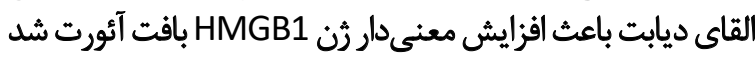

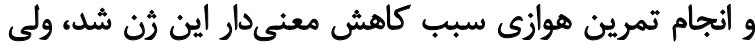

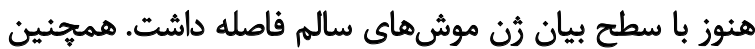

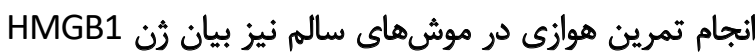

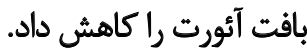

نتايج تحليل واريانس يكطرفه (جدول شماره f) در سطح

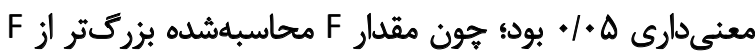

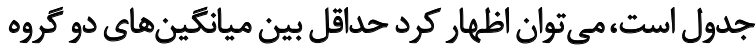


جدول F. نتايج آزمون تحليل واريانس يكطرفه سطوح HMGB1 در كروهاى مختلف يثروشش

\begin{tabular}{|c|c|c|c|c|c|}
\hline ارزش P & ارزش F & ميانكين مربعات & درجات آزادى df & SS مجموع مربعات & منابع تغيير \\
\hline \multirow[t]{3}{*}{$* \ldots$} & $r Y / \circ \Delta r$ & $\cdot 1 \cdot V^{r}$ & $r$ &.$/ T I E$ & بين كروهى \\
\hline & & $\cdot \cdot+r$ & $\lambda$ & /.YY & درون كروهى \\
\hline & & & 11 & . MET & جمع كل \\
\hline
\end{tabular}

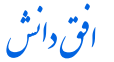

جدول ه. ميانكين \ انحراف استاندارد ميزان كلوكز خون كروهها

\begin{tabular}{|c|c|c|}
\hline \multicolumn{2}{|c|}{ كَلوكز خُون } & \multirow{2}{*}{ كروه/متغير } \\
\hline ميانكين \ انحراف استاندارد & تعداد & \\
\hline $11 . / 11 \pm t / 98$ & 1. & كتثرل \\
\hline$Q T / r \Delta \pm \Delta / \mu$ & 1. & تمرين هوازى \\
\hline rVI/AIEMr/Ar & $1+$ & ديابث \\
\hline IAV/IYEIYY/AY & 1. & ديابت تمرين هوازى \\
\hline
\end{tabular}

جدول \&. نتايج أزمون بيكيرى ثوكى در مورد ميزان كلوكز خون كروهها

\begin{tabular}{|c|c|c|c|c|c|}
\hline سطح معنى دارى & خطاى استاندارد & تفاوت ميانكين (ل-I) & كروه (J) & تروه (I) & مثتير وابسته \\
\hline$+\ldots$ & D/Fet & $-|\varepsilon| / N \ldots$ & كنترل ديابت & & \\
\hline.$|\cdot H|$ & D/Tef & IEIN. & تمرين هوازى & كنترل & \\
\hline $.1 .$. & d/ref & $-W / \cdot Y$ & ديابت تمرين & & ميزان كلوكزَ خُون \\
\hline 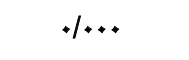 & d/refe & $-97 / M$. & ديابت تمرين & تمرين & \\
\hline$* \ldots$ & D/TEY & AF/GA. & ديابت تمرين & ديابت & \\
\hline
\end{tabular}

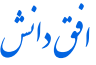

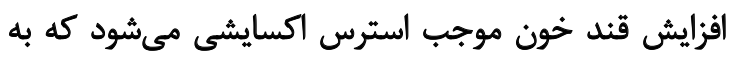

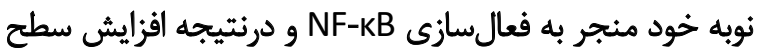

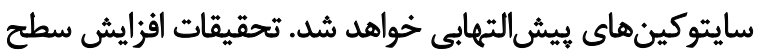

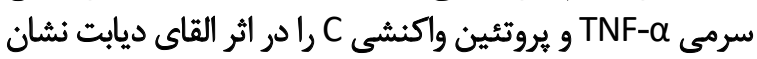
ميدهد [YY]. در مطالعات افزايش معني وردار

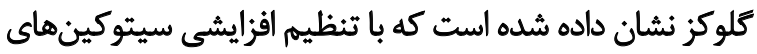

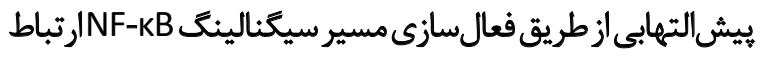

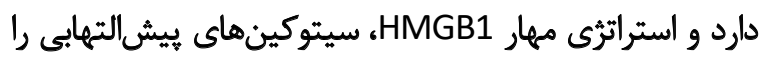

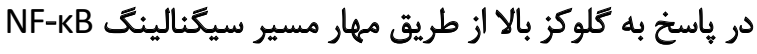

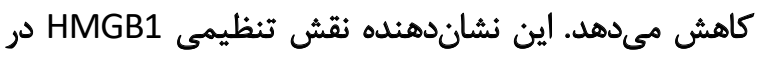

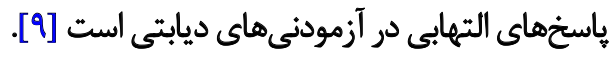

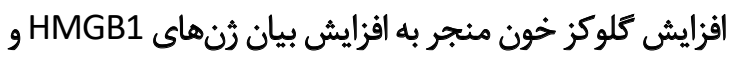
TNF- $\alpha$

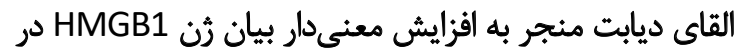

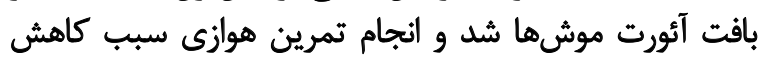

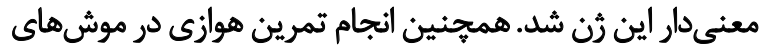

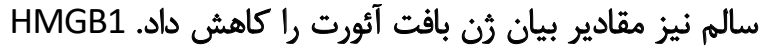

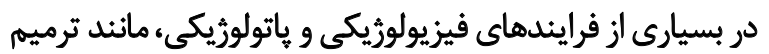
DNA

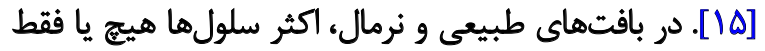

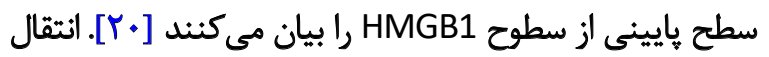

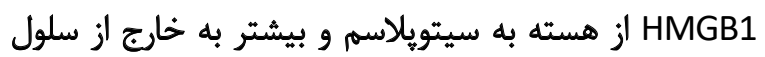
تنهادر شرايط باتولوزيك (ايسكمى، تروما، هاييركليسمى وغيرهات

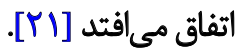




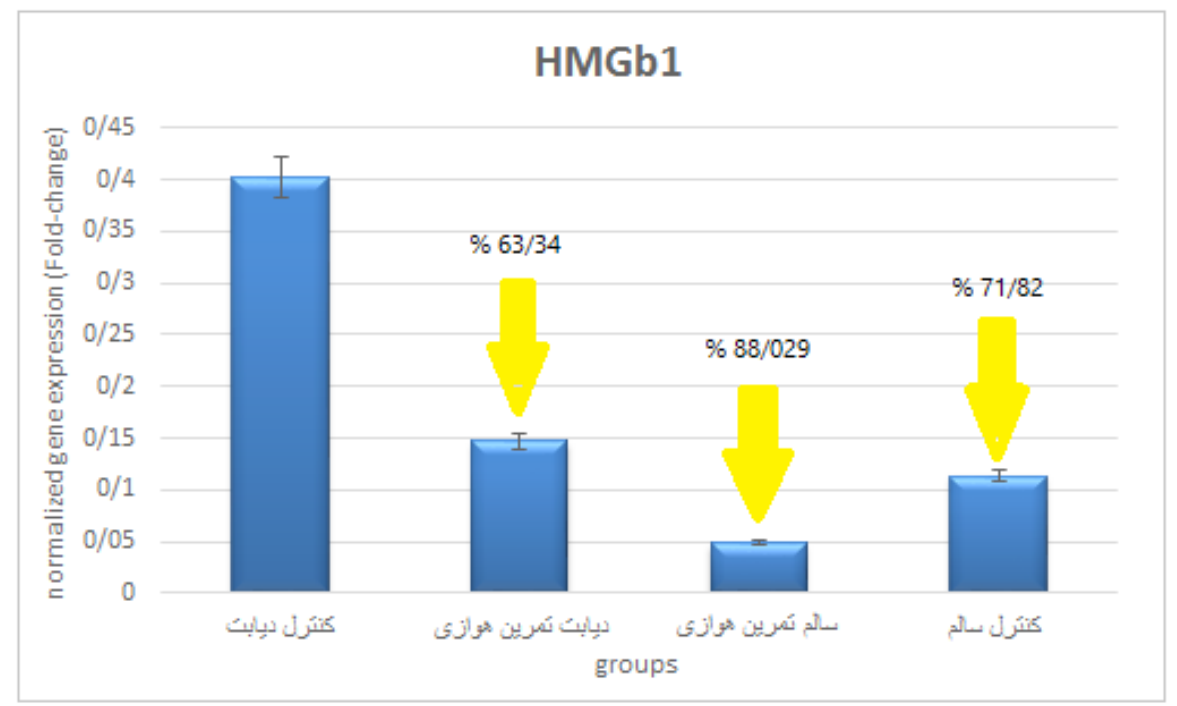

أنّوانث

تصوير ا. مقايسه ميانكين سطوح HMGB1 در كروهان مخثلف يروهش

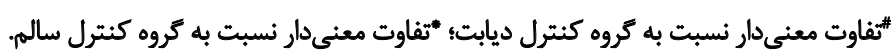

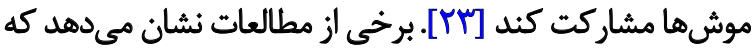

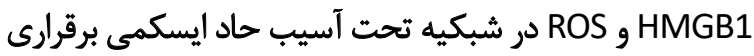

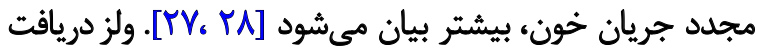

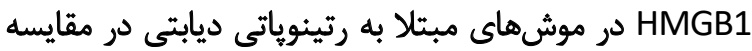

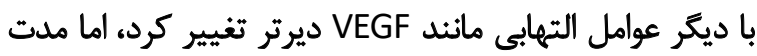

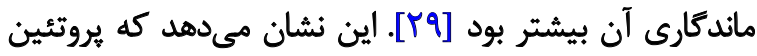

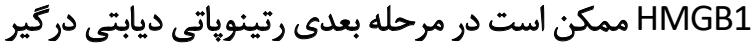

شود. - م

تصور مي شد كه HMGB1 ممكن است در التهاب و تشكيل

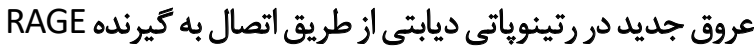

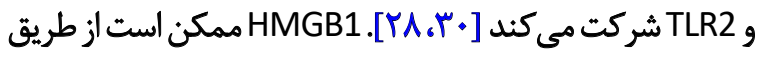

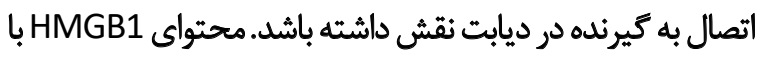

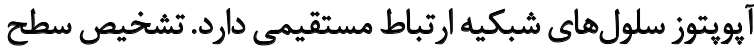
و درمان هدفمند HMGB1

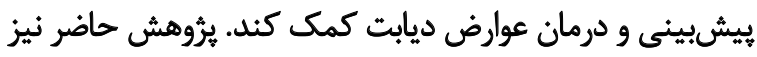

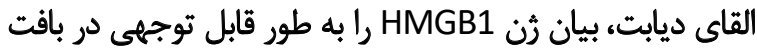

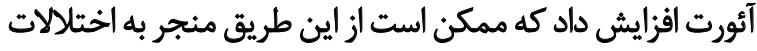

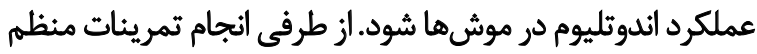

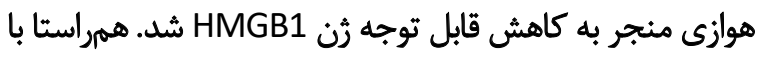

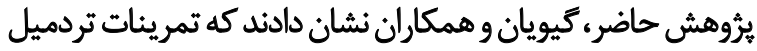

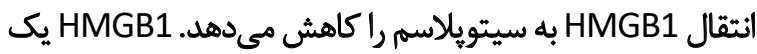

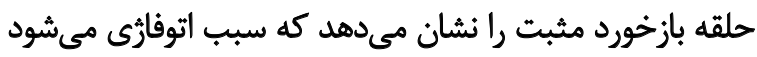

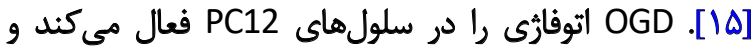

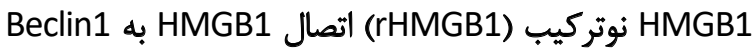

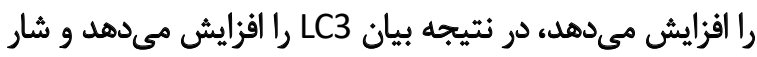

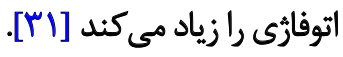
مطالعات بيشين نُشان دادند كه تمرينات تردميل همجينين بر
بيشالتهابى مانند TNF- $\alpha$ به بيامرسانى انسولين در بافتهاى

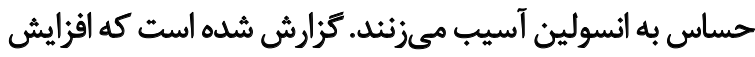
سطوح سيستميك سايتوكين ضدالتهابى اينترلوكين · •ا عضله

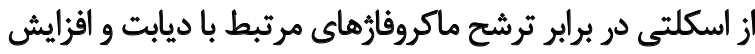
سايتوكين التهابى TNF-

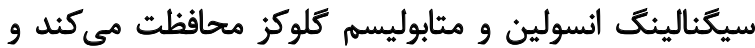

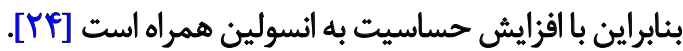
فعاليت ورزشى توليد سايتوكينهاى ضدالتهابي همانند

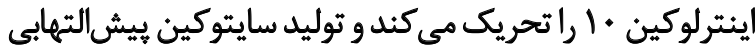

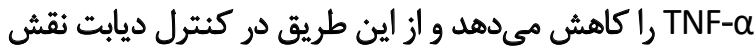

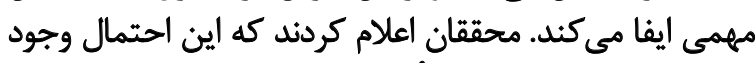

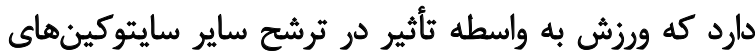

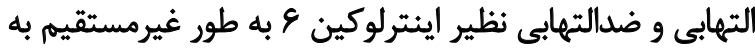

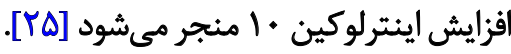

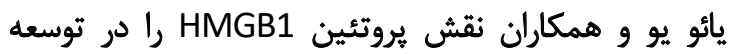

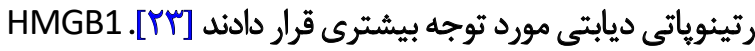

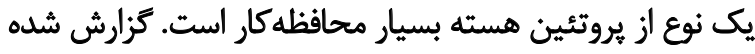

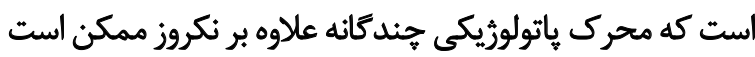

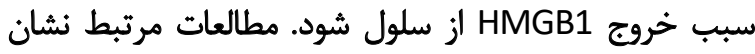

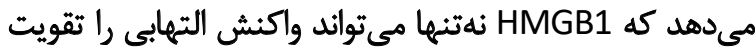

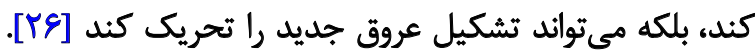

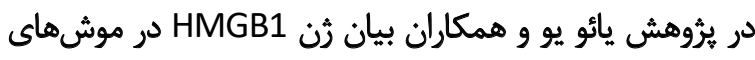

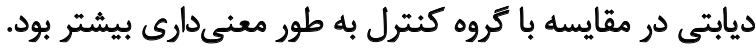

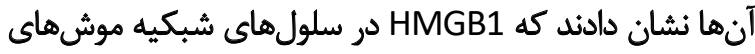
ديابتى

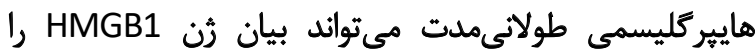

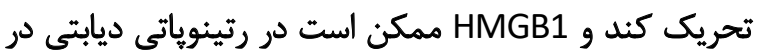


مرودشت و با كد IR.IAU.M.REC.1399.007 انجام شد.

$$
\text { Jlo sols }
$$

اين مقاله از خايان نامه دكترى سميرا حسنيور سليمانى در

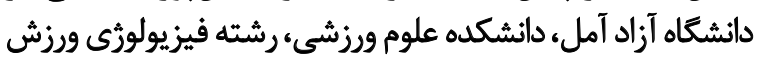
(قلب و عروق تنفس) استخراج و بلون دريافت كمك مالي انجام

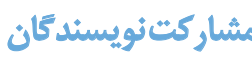

ايده اصلى: آسيه عباسي دلوئي؛ نغارش مقاله و تأييد نهاييى

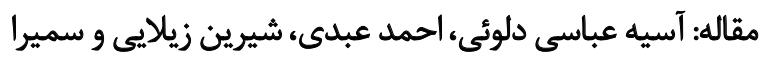

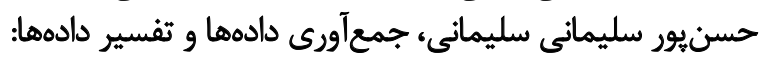

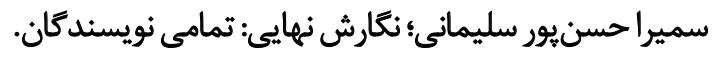

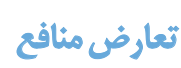

بنابر اظهار نويسئدكان هيجكونه تعارض منافع در اجراى اين يثروهش وجود نداشته است.
بيان سرمى HMGB1 اثر مى كذارد [19] كه اين نشان از وجود

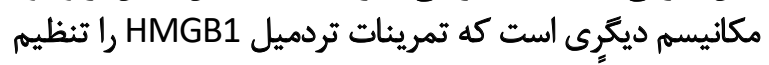

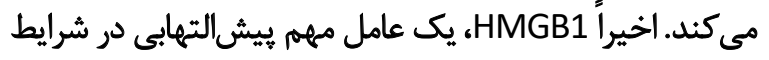

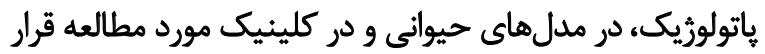

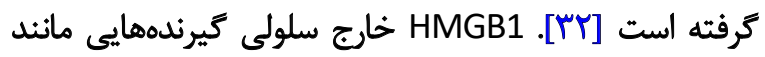

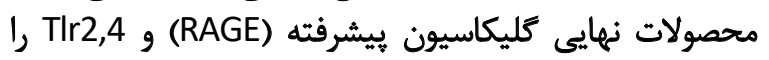

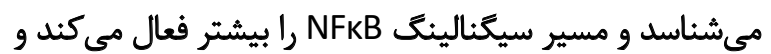

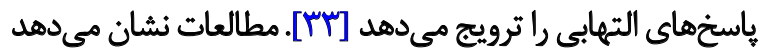

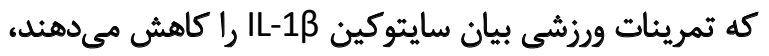

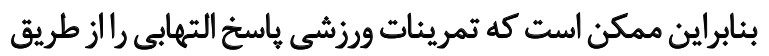

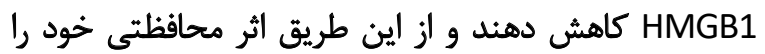

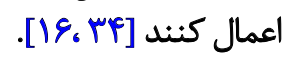

تقى بيكى و همكاران كزارش كردهاند كه تمرين هوازى موجب

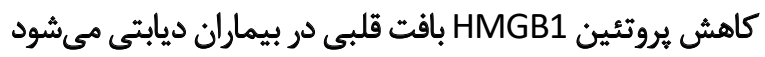

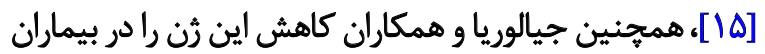

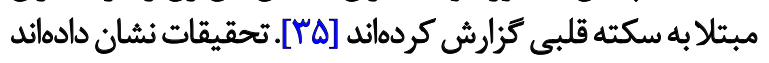

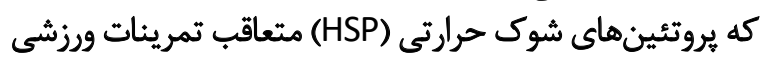

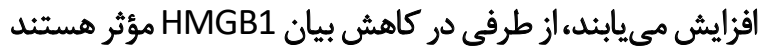

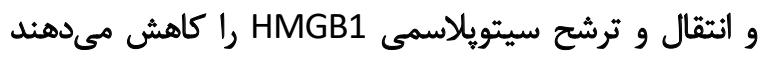

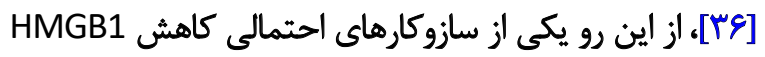

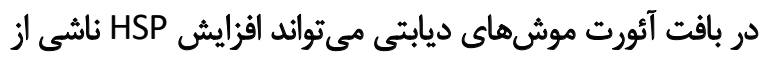
تمرينات هوازى باشد.

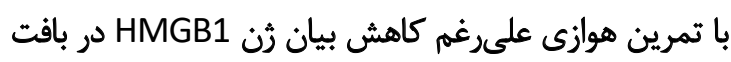

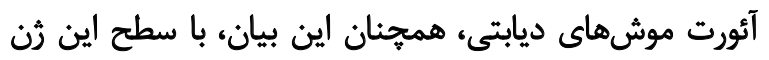

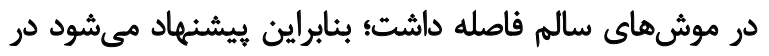

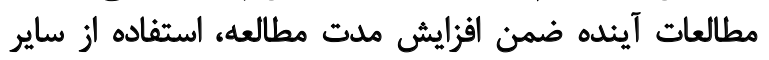

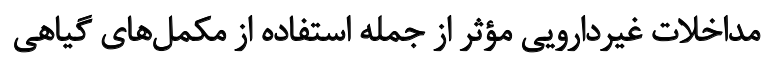

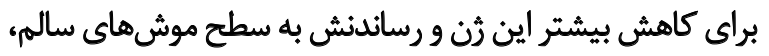

$$
\text { بروسى شود. }
$$

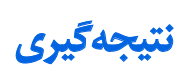

در مطالعه حاضر شش هفته تمرين هوازى منجر به كاهش

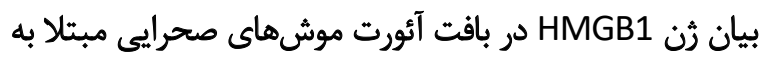

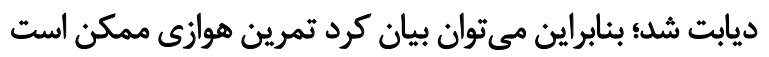

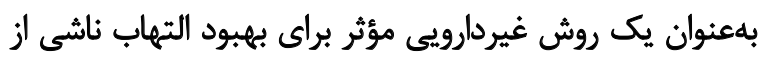

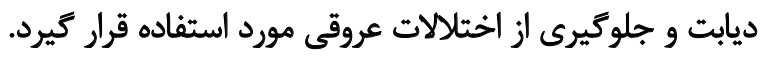

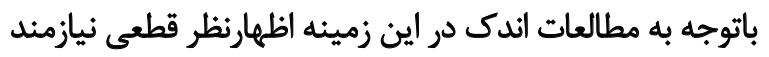
مطالعات بيشتر در اين زمينه است.

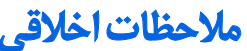
يبروى أز أصول الخاق بئوهش اين تحقيق با تأييد كميته اخلاق در دانشعاه آزاد اسلامى واحد 


\section{References}

[1] Scherrenberg M, Dendale P. Exercise training in diabetes. European Journal of Preventive Cardiology. 2019; 26(7):698-700. [DOI:10.1177/2047487319829674] [PMID]

[2] Wilding JPH. Medication use for the treatment of diabetes in obese individuals. Diabetologia. 2018; 61:265-72. [DOI:10.1007/s00125-0174288-1] [PMID] [PMCID]

[3] Khaleeli E, Peters SR, Bobrowsky K, Oudiz RJ, Ko JY, Budoff MJ. Diabetes and the associated incidence of subclinical atherosclerosisand coronary artery disease: Implications for management. American Heart Journal. 2001; 141(4);637-44. [DOI:10.1067/mhj.2001.113224] [PMID]

[4] Asgary S, Hashemi M, Goli-Malekabadi N, Keshvari M. [The effects of acute consumption of pomegranate juice (Punica granatum L.) on decrease of blood pressure, inflammation, and improvement of vascular function in patients with hypertension: A clinical trial (Persian)]. Journal of Shahrekord University of Medical Sciences. 2015; 16(6):84-91. http:// journal.skums.ac.ir/article-1-1761-en.html

[5] Rader DJ. IL-1 and atherosclerosis: A murine twist to an evolving human story. The Journal of Clinical Investigation. 2012; 122(1):27-30. [DOI:10.1172/JCI61163] [PMID] [PMCID]

[6] Xu YJ, Zheng L, Hu YW, Wang Q. Pyroptosis and its relationship to atherosclerosis. Clinica Chimica Acta. 2018; 476:28-37. [DOl:10.1016/j. cca.2017.11.005] [PMID]

[7] Hui Y, Yin Y, Tian DH. Combination of serum HMGB1 and serum miR-126 achieve high predictive power to detect proliferative diabetic retinopathy: A Chinese population-based study. International Journal of Clinical and Experimental Medicine. 2019; 12(5):5909-14. http://www.ijcem. com/files/ijcem0078585.pdf

[8] Czura CJ, Tracey KJ. Targeting high mobility group box 1 as a late-acting mediator of inflammation. Critical Care Medicine. 2003; 31(1):S46-50. [DOI:10.1097/00003246-200301001-00007] [PMID]

[9] Wang H, Qu H, Deng H. Plasma HMGB1 levels in subjects with obesity and type 2 diabetes: A cross-sectional study in China. PLoS One. 2015; 10(8):e0136564. [DOI:10.1371/journal.pone.0136564] [PMID] [PMCID]

[10] Beckman JA, Paneni F, Cosentino F, Creager MA. Diabetes and vascular disease: Pathophysiology, clinical consequences, and medical therapy: Part II. European Heart Journal. 2013; 34(31):2444-52. [DOI:10.1093/ eurhearti/eht142] [PMID]

[11] Kränkel N, Bahls M, Van Craenenbroeck E, Adams V, Serratosa L, Solberg $\mathrm{EE}$, et al. Exercise training to reduce cardiovascular risk in patients with metabolic syndrome and type 2 diabetes mellitus: How does it work? European Journal of Preventive Cardiology. 2019; 26(7):701-8. [DOI:10.1177/2047487318805158] [PMID]

[12] Yanai H, Adachi H, Masui Y, Katsuyama H, Kawaguchi A, et al. Exercise therapy for patients with type 2 diabetes: A narrative review. Journal of Clinical Medicine Research. 2018; 10(5):365-9. [DOI:10.14740/jocmr3382w] [PMID] [PMCID]

[13] Gleeson M, Bishop NC, Stensel DJ, Lindley MR, Mastana SS, Nimmo MA. The anti-inflammatory effects of exercise: Mechanisms and implications for the prevention and treatment of disease. Nature Reviews Immunology. 2011; 11(9):607-15. [DOI:10.1038/nri3041] [PMID]

[14] Taghibeigi Hoseinabadi H, Esfarjani F, Marandi SM, Karami H. [Effects of eight weeks of aerobic training on expression levels of the HMGB1RAGE/TLR4-NF-kB proinflammatory pathway in cardiac tissue of male rats with hyperglycemia (Persian)]. Iranian Journal of Endocrinology and Metabolism. 2019; 20(5):246-52. http://ijem.sbmu.ac.ir/article1-2477-en.html
[15] Pan G, Jin L, Shen W, Zhang J, Pan J, Cheng J, et al. Treadmill exercise improves neurological function by inhibiting autophagy and the binding of HMGB1 to Beclin1 in MCAO juvenile rats. Life Sciences. 2020; 243:117279. [DOI:10.1016/j.lfs.2020.117279] [PMID]

[16] Shirwaikar A, Rajendran K, Punitha ISR. Antidiabetic activity of alcoholic stem extract of Coscinium fenestratum in streptozotocin-nicotinamide induced type 2 diabetic rats. Journal of Ethnopharmacology. 2005; 97(2):369-74. [DOI:10.1016/j.jep.2004.11.034] [PMID]

[17] Palsamy P, Subramanian S. Reaveratrol, a natural phytoalexin normalizeshyperglyciemia in strepozotocin - nicotinamide induced experimental diabetic rats. Biomedicin \& Phalmacotherapy. 2008; 62(9):598-605. [DOI:10.1016/j.biopha.2008.06.037] [PMID]

[18] Chae CH, Jung SL, An SH, Jung CK, Nam SN, Kim HT. Treadmill exercise suppresses muscle cell apoptosis by increasing nerve growth factor levels and stimulating p-phosphatidylinositol 3-kinase activation in the soleus of diabetic rats. Journal of Physiology and Biochemistry. 2011; 67(2):235-41. [DOI:10.1007/s13105-010-0068-9] [PMID]

[19] Tang D, Kang R, Livesey KM, Cheh CW, Farkas A, Loughran P, et al. Endogenous HMGB1 regulates autophagy. The Journal of Cell Biology. 2010; 190(5):881-92. [DOI:10.1083/jcb.200911078] [PMID] [PMCID]

[20] Wu Y, Xu J, Xu J, Zheng W, Chen Q, Jiao D. Study on the mechanism of JAK2/ STAT3 signaling pathway-mediated inflammatory reaction after cerebral ischemia. Molecular Medicine Reports. 2018; 17(4):5007-12. [DOI:10.3892/mmr.2018.8477]

[21] Kajitani N, Shikata K, Nakamura A, Nakatou T, Hiramatsu M, Makino H. Microinflammation is a common risk factor for progression of nephropathy and atherosclerosis in Japanese patients with type 2 diabetes. Diabetes Research and Clinical Practice. 2010; 88(2):171-6. [DOI:10.1016/j. diabres.2010.01.012] [PMID]

[22] Chen Y, Qiao F, Zhao Y, Wang Y, Liu G. HMGB1 is activated in type 2 diabetes mellitus patients and in mesangial cells in response to high glucose. International Journal of Clinical and Experimental Pathology. 2015; 8(6):6683-91. [PMID] [PMCID]

[23] Yu Y, Yang L, Lv J, Huang X, Yi J, Pei C, et al. The role of High Mobility Group Box 1 (HMGB1) in the diabetic retinopathy inflammation and apoptosis. International Journal of Clinical and Experimental Pathology. 2015; 8(6):6807-13. [PMID] [PMCID]

[24] Hirose L, Nosaka K, Newton M, Laveder A, Kano M, Peake J, et al. Changes in inflammatory mediators following eccentric exercise of the elbow flexors. Exercise Immunology Review. 2004; 10:75-90. [PMID]

[25] Ouchi N, Parker JL, Lugus JJ, Walsk K. Adipokines in inflammation and metabolic disease. Nature Reviews Immunology. 2011; 11(2):85-97. [DOI:10.1038/nri2921] [PMID] [PMCID]

[26] Lupo G, Anfuso CD, Ragusa N, Strosznajder RP, Walski M, Alberghina M. t-Butyl hydroperoxide and oxidized low density lipoprotein enhance phospholipid hydrolysis in lipopolysaccharide-stimulated retinal pericytes. Biochimica et Biophysica Acta (BBA) - Molecular and Cell Biology of Lipids. 2001; 1531(1-2):143-55. [DOI:10.1016/S13881981(01)00102-0]

[27] El-Asrar AM, Missotten L, Geboes K. Expression of high-mobility groups box-1/receptor for advanced glycation end products/osteopontin/early growth response-1 pathway in proliferative vitreoretinal epiretinal membranes. Molecular Vision. 2011; 17:508-18. [PMID] [PMCID]

[28] Chen Y, Sun W, Gao R, Su Y, Umehara H, Dong L, et al. The role of high mobility group box chromosomal protein 1 in rheumatoid arthritis. Rheumatology. 2013; 52(10):1739-47. [DOI:10.1093/rheumatology/ ket134] [PMID] 
[29] Bucolo C, Leggio GM, Drago F, Salomone S. Eriodictyol prevents early retinal and plasma abnormalities in streptozotocin-induced diabetic rats. Biochemical Pharmacology. 2012; 84(1):88-92. [DOI:10.1016/j. bcp.2012.03.019] [PMID]

[30] Naglova H, Bucova M. HMGB1 and its physiological and pathological roles. Bratislava Medical Journal. 2012; 113(3):163-71. [DOI:10.4149/ BLL_2012_039] [PMID]

[31] Wang J, Han D, Sun M, Feng J. Cerebral ischemic post-conditioning induces autophagy inhibition and a HMGB1 secretion attenuation feedback loop to protect against ischemia reperfusion injury in an oxygen glucose deprivation cellular model. Molecular Medicine Reports. 2016; 14(5):4162-72. [DOI:10.3892/mmr.2016.5747] [PMID] [PMCID]

[32] Ye Y, Zeng Z, Jin T, Zhang $\mathrm{H}$, Xiong $\mathrm{X}$, Gu L. The role of high mobility group box 1 in ischemic stroke. Frontiers in Cellular Neuroscience. 2019; 13:127. [DOI:10.3389/fncel.2019.00127] [PMID] [PMCID]

[33] Lok KZ, Basta M, Manzanero S, Arumugam TV. Intravenous immunoglobulin (IVIg) dampens neuronal toll-like receptor-mediated responses in ischemia. Journal of Neuroinflammation. 2015; 12:73. [DOI:10.1186/ s12974-015-0294-8] [PMID] [PMCID]

[34] Zhang Y, Cao RY, Jia X, Li Q, Qiao L, Yan G, et al. Treadmill exercise promotes neuroprotection against cerebral ischemia-reperfusion injury via downregulation of pro-inflammatory mediators. Neuropsychiatric Disease and Treatment. 2016; 12:3161-73. [DOI:10.2147/NDT.S121779] [PMID] [PMCID]

[35] Giallauria F, Cirillo P, D'agostino M, Petrillo G, Vitelli A, Pacileo M, et al. Effects of exercise training on high-mobility group box-1 levels after acute myocardial infarction. Journal of Cardiac Failure. 2011; 17(2):10814. [DOI:10.1016/j.cardfail.2010.09.001] [PMID]

[36] Atalay M, Oksala NKJ, Laaksonen DE, Khanna S, Nakao C, Lappalainen J, et al. Exercise training modulates heat shock protein response in diabetic rats. Journal of Applied Physiology. 2004; 97(2):605-11. [DOI:10.1152/japplphysiol.01183.2003] [PMID] 